Rev Chil Salud Pública 2012; Vol 16 (1): 10

Editorial invitada

\section{Regulación en bioética y la necesaria participación}

En el Ministerio de Salud (Minsal) se encuentran los siguientes documentos en diferentes etapas de gestión y promulgación:

- Reglamento de Comités de Ética en Investigación, según mandato de la Ley 20120.

- Redacción final de la Ley sobre Derechos y Deberes en Salud, que lleva más de 8 años de gestación.

- Reglamento de Comités de Ética Asistencial, cuya preparación es intermitente, habiendo disponible un borrador fechado en 2008.

Estos documentos, han merecido numerosos y reiterados reparos de la Sociedad Chilena de Bioética, así como de personas vinculadas por idoneidad y activa participación al quehacer bioético académico y práctico tanto nacional como latinoamericano. Estos reparos han sido expresados en Mesas de Trabajo convocadas por el Ministerio de Salud, en comunicaciones al Ministerio, en asesorías solicitadas por el Poder Legislativo y, muy recientemente, en Jornadas de la Sociedad Chilena de Bioética.

La democratización de estas importantes iniciativas para la regulación ética de actividades médicas clínicas y de investigación con seres humanos (biomédica en lo principal, pero también con alcances para estudios de psicología, sociología, antropología e historia), ha sido deficiente. La inmensa mayoría de las objeciones, reparos o enmiendas sugeridas por personas de reconocida solvencia en estos temas, no ha sido considerada en los textos finales, los cuales aparecen con serias deficiencias jurídicas, éticas y administrativas.

El actuar inconsulto y la indisposición a acoger críticas y enmendar errores, se da también en disposiciones que emanan del Minsal con respecto a políticas sanitarias más puntuales, como la obligatoriedad de examen VIH en embarazadas, la intromisión oficial en materias de confidencialidad (en VIH/Sida) y la modificación de la Ley de Trasplantes que obliga a documentar la intención de no donante. Las decisiones del Minsal muestran que no considera amplios debates académicos publicados en la literatura pertinente ni experiencias internacionales que, por ejemplo, desaconsejan la obligatoriedad del examen de $\mathrm{VIH}$ por no tener ventajas epidemiológicas pero sí riesgos éticos importantes, incluso en naciones con alta incidencia de infección, lo cual no es el caso en Chile.

La ciudadanía se enfrenta con decisiones y disposiciones oficiales tomadas a espaldas suyas, produciéndose discrepancias importantes entre el discurso oficial y la realidad cotidiana: el Auge/GES promete "atención médica, universal e integral" $y$, sin embargo, el ciudadano chileno continúa pagando de su bolsillo el $40 \%$ de sus gastos en salud.

La Ley 20.120 requiere, además, la formación de la "Comisión Nacional de Bioética", un instrumento fundamental de reflexión y participación ciudadana, que ya existe en más de un centenar de países, y cuya importancia motiva a Unesco para ofrecer la asesoría de su programa ABC (Assisting Bioethics Commissions). Sin embargo, desde el 2006 en que se dictó la Ley no se sabe de iniciativa concreta alguna para crear esta Comisión. Más grave es que el Minsal ha emitido opiniones e intenciones que distorsionan los objetivos de una Comisión Nacional, y desconoce la asesoría idónea presentada oportunamente al Legislativo, poniendo en riesgo el más importante, si no el único, instrumento efectivo de participación ciudadana en materias de bioética que a todos atañen. 